\title{
CHANGES IN SECONDARY METABOLITES PROFILES AND BIOLOGICAL ACTIVITY OF THE FRESH FRUITING BODIES OF Stereum hirsutum EXPOSED TO HIGH-DOSE UV-B RADIATION
}

\author{
SOLANGE TORRES ${ }^{a}$ - JAIME R. CABRERA-PARDO ${ }^{a}$ - FELIPE ALONSO ${ }^{a}$ - EVELYN BUSTOS ${ }^{a}$ - CLAUDIA \\ PÉREZ ${ }^{a}$ GOETZ PALFNER ${ }^{b}$ - VÍCTOR HERNÁNDEZ ${ }^{a}$ - EUGENIO URIARTE ${ }^{c}$ - JOSÉ BECERRA ${ }^{a *}$
}

${ }^{a}$ Laboratory of Chemistry of Natural Products, Department of Botany, University of Concepción, Casilla 160-C, Concepción, Chile. ${ }^{b}$ Laboratory of Micology and Mycorrhizae, Department of Botany, University of Concepción. Concepción. Chile.

${ }^{c}$ Department of Organic Chemistry, Faculty of Pharmacy, University of Santiago de Compostela. 15782, Santiago de Compostela, Spain.

\begin{abstract}
The present study aims to investigate the effects of ultraviolet radiation (type B) on the steroid and fatty acids content, phenolic compounds and biological activities of Stereum hirsutum wild fruiting bodies, which has been used by both Chinese and Korean folk medicine to treat cancer and recently as functional food. From another perspective, the distribution of steroid derivatives as well as fatty acids underwent significant changes after UV exposure over time. In our model of study UV-B radiation induced a decrease in the relative abundance of ergosterol derivatives while squalene increased. We also detected that UVB radiation (1.2 W $\mathrm{m}^{-2}$ ) enhanced the antioxidant activity of Stereum hirsutum, with the acetonic extract after 48 hours of radiation the most efficient with a half-maximal inhibitory concentration $\left(\mathrm{IC}_{50}\right.$ ) of $339.9 \mu \mathrm{g} / \mathrm{mL}$. Gas-mass chromatography (GC-MS) analysis at this 48 hours stage revealed a high content of phenolic compounds (70\%). We observed a decrease in the antibacterial activity against Escherichia coli, Salmonella typhi and Salmonella typhimurium compared to their respective controls. The study concludes that UV-B influences the pathway of secondary metabolites to induce changes metabolic in the composition of sterols and fatty acids and increasing the abundance of antioxidant compounds in S. hirsutum.
\end{abstract}

Keywords: saprophytic fungi; UV-B radiation; secondary metabolites; antibacterial properties; antioxidant activity.

\section{INTRODUCTION}

The current climate change is a global phenomenon characterized by a variety of factors including alteration in temperatures, carbon dioxide concentrations and increased surface ultraviolet-B (UV-B 290-320nm) radiation. ${ }^{1}$ High exposure to UV-B rays produces negative effects in microorganisms by damaging DNA and biological membranes, altering metabolite production and causing morphogenetic modifications. ${ }^{2}$ In spite of this, the metabolic plasticity of microorganisms, especially fungi, enhances their ability to survive under the oxidant environment produced by UV-B radiation. To better understand this plasticity, efforts have been made to investigate the metabolic responses in fungi upon UV energy exposure. These endeavours have shown that UV radiation promotes the conversion of ergosterol to vitamin $\mathrm{D}_{2} \cdot{ }^{3}$ Due to its beneficial implications, this process has been investigated aiming to maximize the amount of vitamin $\mathrm{D}_{2}$ in edible mushrooms. 4,5

The south Chilean environment presents special climate conditions that house a unique microorganism community. ${ }^{6}$ Currently, around 3,000 fungi species have been identified in southern Chile and the actual number of fungi species inhabiting this territory could easily reach 30,000. Macrofungi such as Ascomycota and Basidiomycota can be found across the country, ${ }^{7}$ providing an extensive biological source to investigate the effect of environmental stressors (e.g. UV-B radiation) on fungal metabolic profiles.

Stereum hirsutum is a basidiomycete directly involved in Esca, a destructive disease in grapevine. This ubiquitous microorganism lives on deadwood, hardwood or dead leaves, ${ }^{8}$ playing an important role in the wood degradation process. S. hirsutum successfully lives throughout Chile and has shown both relevant biological activity and nutraceutical properties. Due to this, recently been reported that $S$. hirsutum could be used as functional food. ${ }^{9}$ In the course of our research program investigating fungi metabolites from Chilean environments we became interested in exploring the effect of UV-B exposure on both the metabolites profile and antioxidant and antibacterial activities of $S$. hirsutum wild fruiting bodies.

\section{MATERIAL AND METHODS}

\section{Sampling}

Fresh fruiting bodies of Stereum hirsutum were collected from the dead wood in a native forest of Nothofagus species located in the Bío Bío province in the South-Central Chile (latitude, 36 $50^{\prime} 15.7^{\prime \prime} \mathrm{S}$ and longitude, $73^{\circ} 01^{\prime} 30.8^{\prime \prime}$ WO). A sample of S. hirsutum was identified according to the wood substrate in which the organism was found and the macroscopic characteristics of its fruiting bodies. These included orange color, upper surface covered with villi and the lower, bright orange coloured surface.

\section{Exposure to UV-B}

Fruiting bodies of S. hirsutum growing on wood of Nothofagus were irradiated with a UV-B lamp (Broadband TL20W/12 RS SLV, Philips), at $1.2 \mathrm{~W} \mathrm{~m}^{-2}$ during $48 \mathrm{~h}$. Samples (1.5 g of carpophore) were subjected to radiation at different times $(0,6,24$ and $48 \mathrm{~h})$, affording the total extracts. The radiation source was positioned at $40 \mathrm{~cm}$ from the samples in study. The control experiment (time 0 ) corresponds to the sample that was not exposed to radiation. ${ }^{10}$

\section{Obtention extracts from $S$. hirsutum fruiting bodies}

The samples previously obtained were extracted with $10 \mathrm{~mL}$ of acetone. The extraction process required $5 \mathrm{~min}$ of sonication followed by filtration. The organic solvent was then evaporated under vacuum using a rotary evaporator (Heidolph), obtaining the following crude yields for each sample: $0 \mathrm{~h}(5 \mathrm{mg}), 6$ $\mathrm{h}(3.6 \mathrm{mg}), 24 \mathrm{~h}(3.8 \mathrm{mg})$ y $48 \mathrm{~h}(3.5 \mathrm{mg})$. These extracts were disolved in ethyl acetate $(1 \mathrm{~mL})$ and injected to a GC-MS for analysis.

\section{Gas chromatography mass spectrometry (GC-MS) analysis}

The irradiated and non-irradiated acetonic extracts were analysed with a gas chromatograph (Agilent 7890) mass spectrometer detector (Agilent 5975) equipped with an automatic Agilent injector and a capillary column HP5-MS (J\&W Scientific capillary column $30 \mathrm{~m}$ x $0.25 \mathrm{~mm}$ id and a melted silica film with thickness of $0.25 \mathrm{~mm}$ ). Helium was used as carrier gas, using a $1.5 \mathrm{~mL} / \mathrm{min}$ flow. The initial temperature was $60^{\circ} \mathrm{C}$ during 5 minutes. The temperature increased in an $8{ }^{\circ} \mathrm{C} / \mathrm{min}$ pace until $250^{\circ} \mathrm{C}$, steadied for $15 \mathrm{~min}$. The temperature of the injector and detector, in scan mode, was set at $250{ }^{\circ} \mathrm{C}$ and $300^{\circ} \mathrm{C}$, respectively. The mass range scanned covered from 50 to $500 \mathrm{amu}$. The electron impact ionization mode was set at $70 \mathrm{eV}$. The structure of the reported compounds was assessed by comparing the obtained fragmentation patterns with the NIST.05 Chemstation database. The chromatograms were analysed and abundance relative percentages of the compounds were calculated. The structures of the compounds were designed using the program $\mathrm{ACD} /$ ChemSketch.

\section{Antibacterial activity}

The agar diffusion test was employed to assess the biological activity of the acetonic extracts against Escherichia coli, Staphylococcus aureus, Bacillus subtilis, Pseudomonas aeruginosa, Salmonella typhi and Salmonella typhimurium. These microorganisms were grown in trypticase soy broth during $24 \mathrm{~h}$ at $37^{\circ} \mathrm{C}$. Petri dishes containing trypticase agar were inoculated using a 
bacterial suspension of $10^{8} \mathrm{UFC} / \mathrm{mL}$. Paper discs containing $60 \mu \mathrm{g}$ of acetonic extract were deposited onto the previously prepared dishes. ${ }^{11}$ Methanol + Tween $1 \%$ and imipenem $(10 \mu \mathrm{g} / \mathrm{mL})$ were used as negative and positive control, respectively.

\section{DPPH scavenging activity assay}

The antioxidant activity of the extracts was measured on the basis of the scavenging activity of the stable 1, 1- diphenyl - 2-picrylhydrazyl (DPPH) free radical according to the method described in the literature with slight modifications. ${ }^{12} 1 \mathrm{~mL}$ of $100 \mu \mathrm{M}$ DPPH solution in methanol was mixed with $50 \mu \mathrm{L}$ of acetonic extracts of varying concentrations $(100,300,600 \mathrm{y} 900 \mu \mathrm{g} /$ $\mathrm{mL})$. TROLOX solution were added to $1 \mathrm{~mL}$ of DPPH $(100 \mu \mathrm{M})$ and was used as reference standard. Methanol served as blank sample and mixture of $1 \mathrm{~mL}$ solvent and $1 \mathrm{~mL}$ DPPH solution was used as control. The reaction was carried out in triplicate and the decrease in absorbance was measured at $517 \mathrm{~nm}$ after 30 minutes in dark using UV-Vis spectrophotometer. The inhibition \% was calculated using the following formula:

DPPH Scavenging effect $(\%)=[($ Acontrol - Asample $) \div$ Acontrol $] \times 100$

$\mathrm{A}_{\text {Control: }}:$ is the absorbance of the control

$\mathrm{A}_{\text {Sample }}:$ is the absorbance of the sample

\section{RESULTS AND DISCUSSION}

Wild fruiting bodies of S. hirsutum were obtained near the University of Concepcion, Concepcion Chile. The acetonic extract of the fruiting bodies was used for GC-MS analysis of metabolites. Figure 1 shows the relative abundance of ergosterol derivatives and squalene at 0,6 and $24 \mathrm{~h}$ of UV-B radiation time. Before UV-B radiation, the steroids profile is the following: squalene $(6.5 \%)$, dehydroergosterol acetate (4.5\%), dehydroergosterol (4.8\%), ergosterol (39\%), dihydroergosterol $(2.2 \%)$ and ergostenol (3.4\%) (Figure 2). The steroid distribution suffers changes upon UV-B radiation exposure. The relative abundance of ergosterol and its derivatives decreases over time, illustrated by the following data after $24 \mathrm{~h}$ of UV-B radiation: dehydroergosterol acetate (2.7\%), dehydroergosterol (2.1\%), ergosterol, dihydroergosterol and ergostenol are almost undetectable. On the contrary, GC-MS analysis of S. hirsutum after $24 \mathrm{~h}$ of irradiation reveals an increase in squalene abundance (18.6\%).

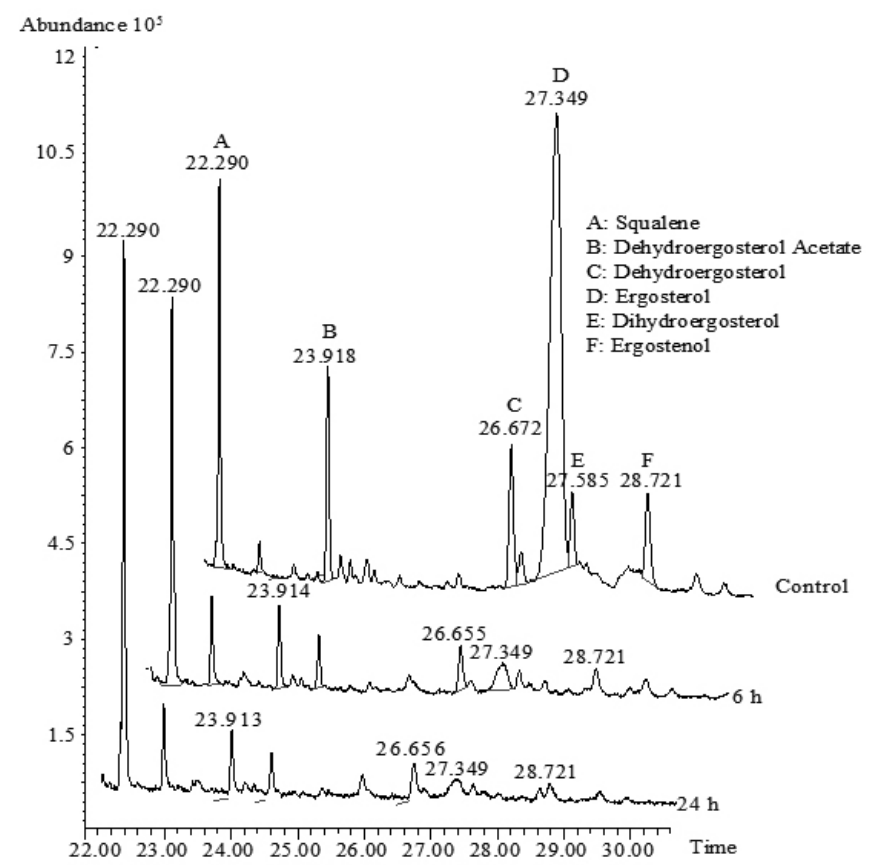

Figure 1. GC-MS steroid profile of S. hirsutum at different UV radiation times

It has been well documented that UV-B energy promotes the conversion of ergosterol to vitamin $\mathrm{D}_{2}$ in fungi, which could lead to subsequent squalene depletion after UV-B exposure. Our results nonetheless suggest that UV-B radiation might be affecting the ergosterol biosynthetic pathway, resulting in the accumulation of squalene, according to GC-MS data. Crucial experiments to definitively address this observation are currently in progress and will be reported at due course.

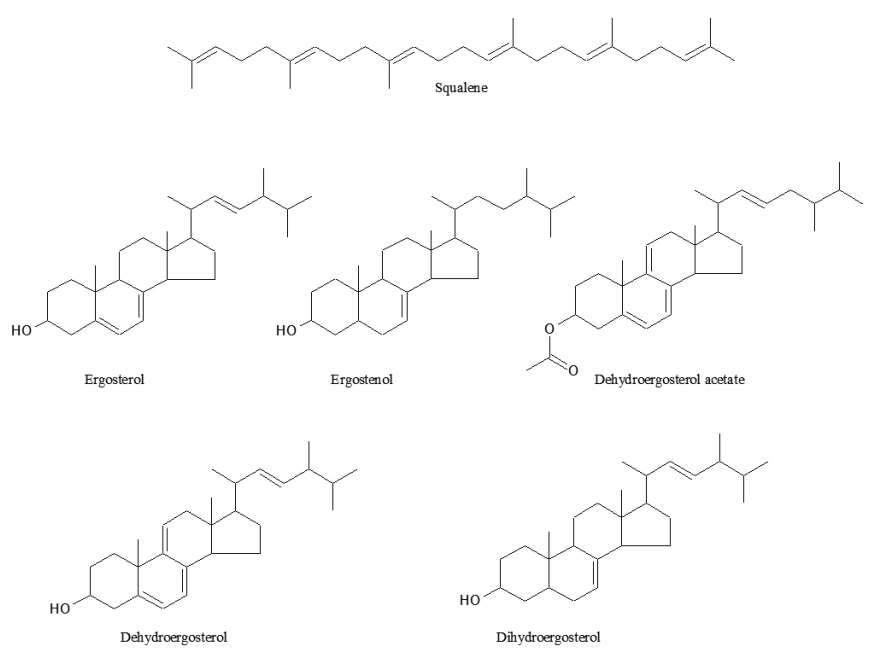

Figure 2. Sterol structures present in the acetonic extract before UV-B radiation.

The UV-B radiation produces excess ROS resulting in oxidative stress. ${ }^{13}$ On this basis, is important to determine presence antioxidant activity in irradiated fruiting bodies. DPPH radical scavenging activity is one of the most widely used method for screening the antioxidant activity of plant and fungi extracts. We also investigated the ability of UV-B irradiated S. hirsutum fruiting bodies to neutralize radicals using the DPPH assay as depicted in Figure 3.

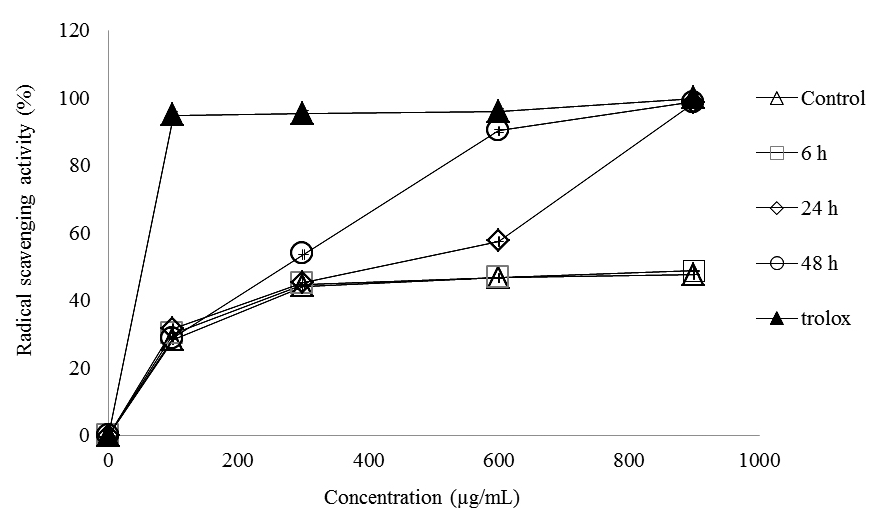

Figure 3. DPPH scavenging assay of acetonic extract of $S$. hirsutum at different UV radiation times.

Extract concentrations from 100 to $900 \mu \mathrm{g} / \mathrm{mL}$ were evaluated. The highest DPPH scavenging activity was observed in acetonic extract to 48 hours of exposition UV-B radiation time with a $90.2 \%$ at $600 \mu \mathrm{g} / \mathrm{mL}$ and $99.9 \%$ at $900 \mu \mathrm{g} / \mathrm{mL}$ compared to standard solution (TROLOX) (Figure 3). The $\mathrm{IC}_{50}$ value of the $S$. hirsutum extract at $48 \mathrm{~h} \mathrm{UV}-\mathrm{B}$ exposure stage is $339.9 \mu \mathrm{g} / \mathrm{mL}$, as depicted in Table 1. However, low DPPH scavenging activity was found in acetonic extract to 6 hours of exposition UV-B radiation time with a $48.7 \%$ at $900 \mu \mathrm{g} / \mathrm{mL}$.

The fatty acid profile underwent changes upon UV-B irradiation. Figure 4(a) shows the relative abundance of fatty acid derivatives at 0,6 and $24 \mathrm{~h}$ of UV-B radiation time. The fatty acid profile in the control sample was as follows: hexadecanoic acid (7.2\%), octadecadienoic acid $(4.7 \%)$, octadecenoic acid $(1.0 \%)$ and octadecanoic acid $(0.7 \%)$. UV-B exposure affected the distribution of fatty acids reducing the di-unsaturated fatty acid and concomitantly increasing the mono-unsaturated and saturated fatty acid abundances in S. hirsutum fruiting bodies. The GC-MS data at $24 \mathrm{~h}$ of radiation rendered the following profile: hexadecanoic acid (10.1\%), octadecadienoic 
acid $(2.8 \%)$, octadecenoic acid $(2.1 \%)$ and octadecanoic acid $(2.2 \%)$. The oxidant environment caused by UV-B radiation reacts with the electron rich octadecadienoic acid, reducing its abundance.

Table 1. $\mathrm{IC}_{50}$ values of $S$. hirsutum extract at different UV-B radiation times to scavenge DPPH radical.

\begin{tabular}{|c|c|c|}
\hline Sample & $\mathbf{I C}_{\mathbf{5 0}} \mathbf{( \mu \mathbf { g } / \mathbf { m L } )}$ & $*$ SD \\
\hline Trolox & 7.03 & \pm 0.21 \\
\hline Control & 768.2 & \pm 1.7 \\
\hline $6 \mathrm{~h}$ & 751.4 & \pm 1.9 \\
\hline $24 \mathrm{~h}$ & 415.8 & \pm 0.2 \\
\hline $48 \mathrm{~h}$ & 339.9 & \pm 0.9 \\
\hline
\end{tabular}

*Data are mean $\pm \mathrm{SD}$ for three replications.

After $48 \mathrm{~h}$ of UV-B exposure, the antioxidant activity was remarkable at 600 and $900 \mu \mathrm{g} / \mathrm{mL}$, achieving around $90 \%$ of efficiency (Figure 3). Metabolite analysis at $48 \mathrm{~h}$ revealed a high abundance of phenolic derivatives $(70 \%)$ corresponding to the percentage of relative abundance. This explains the enhanced antioxidant activity at this radiation stage, as shown in Figure 4(b). These phenolic compounds were not detected prior to $48 \mathrm{~h}$ of UV-B radiation. Compounds involved in photoprotection are synthetized to counteract ROS as shown in the present study.

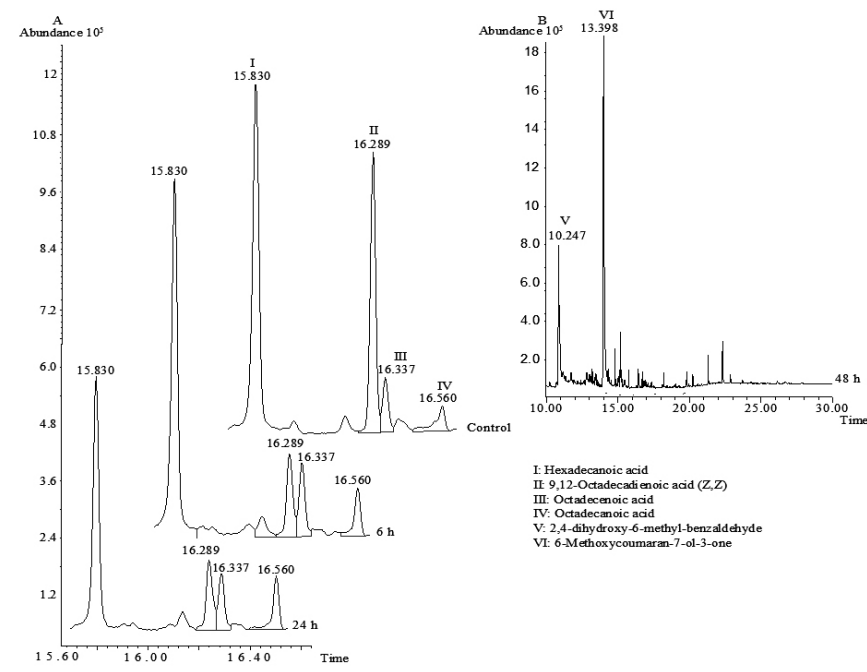

Figure 4. GC-MS profile of S. hirsutum at different UV radiation times. A. Fatty acids trace at 6 and $24 \mathrm{~h}$ of UV-B radiation. B. Phenolic compounds trace at $48 \mathrm{~h}$ of UV-B radiation.

As observed above, UV-B radiation led to changes in the metabolite profile in $S$. hirsutum fruiting bodies. Thus, we wondered whether the antibacterial ability of this fungus against Gram positive and negative bacteria would also be affected. Table 2 shows the bioactivity of the acetonic extract against a variety of medicinally relevant strains including E. coli, P. aeruginosa, $S$. typhi, $S$. typhimurium and $S$. aureus. The UV-B radiation led to a decrease in the antibacterial activity against E. coli, S. typhi and S. typhimurium.

Table 2. Antibacterial activity of acetonic extracts of $S$. hirsutum at different UV-B radiation times.

\begin{tabular}{|c|c|c|c|c|c|}
\hline & & Diameter (mm) & & Salmonella \\
\hline Extracts/Species & Escherichia coli & $\begin{array}{c}\text { Pseudomonas } \\
\text { aeruginosa }\end{array}$ & Salmonella typhi & Staphylococcus aureus \\
\hline$-\mathrm{UVB}$ & $20.0 \pm 0.0$ & NA & $20 \pm 0.58$ & $15 \pm 0.0$ & NA \\
\hline $6 \mathrm{~h}$ & $15.0 \pm 0.0$ & NA & $15 \pm 0.0$ & NA & NA \\
\hline $24 \mathrm{~h}$ & NA & NA & NA & NA & NA \\
\hline $48 \mathrm{~h}$ & NA & NA & NA & $12 \pm 0.0$ & $30 \pm 1.15$ \\
\hline Control $(+)$ & $15.0 \pm 0.0$ & $13 \pm 0.58$ & $30 \pm 0.58$ & NA & NA \\
\hline Control $(-)$ & NA & NA & NA & &
\end{tabular}

NA: No Activity; positive control (+): Imipenem $10 \mu \mathrm{g}$; negative control (-): Methanol + Tween 1\%. Data are mean $\pm \mathrm{SD}$ for three replications.

These results agree with previous work in a decrease in the ability competitive of organism under UV-B radiation. ${ }^{14}$ On the other hand, UV-B radiation did not produce any changes in the antibacterial activity against $P$. aeruginosa and $S$. aureus. Previous studies have indicated that fungi exhibit light-mediated activity biological against different microorganism and may lead to altered microbial community structure. ${ }^{15}$

\section{CONCLUSION}

We have evaluated the effect of UV-B radiation on the metabolite profile, antioxidant activity and antibacterial activity of $S$. hirsutum fruiting bodies obtained from southern Chile. We observed substantial changes in steroid derivatives. Specifically, the relative abundance of ergosterol and its derivatives decreased upon UV-B radiation, while squalene increased. Antioxidant ability was also tested and we observed that $900 \mu \mathrm{g} / \mathrm{mL}$ of $S$. hirsutum acetonic extract at $48 \mathrm{~h}$ of UV-B radiation showed the highest ability to neutralize DPPH radicals $\left(\mathrm{IC}_{50}=339.9 \mu \mathrm{g} / \mathrm{mL}\right)$. According to GC-MS analysis, the oxidant environment generated by UV-B radiation reduced the abundance of di-unsaturated fatty acids at $24 \mathrm{~h}$ of radiation exposure. After $48 \mathrm{~h}$, a dramatic increase in the abundance of phenolic compounds was observed (70\%), which is in accordance with the enhanced antioxidant activity at the corresponding irradiation time. Finally, UV-B radiation induced changes in the antibacterial activity of $S$. hirsutum with a decrease in the antibacterial activity against $E$. coli, S. typhi and S. typhimurium.

\section{ACKONWLEDGMENTNS}

We thank CONICYT-Chile for supporting Solange Torres in her Ph.D. training. We would like to express our gratitude to the financial supported provided by project CONICYT-PAI N ${ }^{\circ} 781412001$, FONDECYT N ${ }^{\circ} 1151028$ and VRID University of Concepción.

\section{REFERENCES}

1. D. Johnson, Res. Microbiol. 154, 315, (2003).

2. KJ. Duguay, JN. Klinoromos, Appl Soil Eco. 14, 157, (2000).

3. VJ. Jasinghe, CO. Perera, Food Chem. 95, 638, (2006).

4. A. Teichman, PC. Dutta, A. Staffas, M. Jagerstad, LWT- Food Sci Technol. 40, 815, (2007).

5. VJ. Jasinghe, CO. Perera, Food Chem. 92, 541, (2005). 
6. C. Villagrán, C. Le-Quesne, JC. Aravena, H. Jiménez, F. Hinojosa, Giess Geogr Schr. 15, 227, (1998).

7. G. Palfner, Aust Syst Bot. 19, 431, (2006).

8. PM. Kirk, PF. Cannon, DW. Minter, JA. Stalpers Dictionary of the Fungi, CABI Europe - UK, 2008.

9. K. Ma, L. Bao, J. Han, T. Jin, X. Yang, F. Zhao, S. Li, F. Song, M. Liu, H. Liu, Food Chem. 143, 239, (2014).
10. U. Krings, R. Berger, Food Chemistry 149, 10, (2014).

11. BS. Yun, IK. Lee, Y. Cho, S. Cho, ID. Yoo. J Nat Prod. 65, 786, (2002)

12. G. Pawle, SK. Singh, Curr Res Environ Appl Mycol. 4, 1, (2014).

13. WY. Huang, YZ. Cai, J. Xing, H. Corke, M. Sun, Econ Bot. 61, 4, (2007).

14. J. Becerra, M. Silva, J.Becerra, Rev Latinoamer Quím. 42, 77, (2014).

15. D. Rule, N. Cheeptham, Int J Speleol. 42, 147, (2013). 